\title{
Uric acid induces fat accumulation via generation of endoplasmic reticulum stress and SREBP-1c activation in hepatocytes
}

\author{
Yea-Jin Choi ${ }^{1}$, Hyun-Soo Shin ${ }^{1}$, Hack Sun Choi ${ }^{1}$, Joo-Won Park ${ }^{2}$, Inho Jo ${ }^{3}$, Eok-Soo Oh ${ }^{4}$, Kang-Yo Lee ${ }^{5}$, \\ Byung-Hoon Lee ${ }^{5}$, Richard J Johnson ${ }^{6}$ and Duk-Hee Kang ${ }^{1}$
}

Non-alcoholic fatty liver disease (NAFLD) is currently one of the most common types of chronic liver injury. Elevated serum uric acid is a strong predictor of the development of fatty liver as well as metabolic syndrome. Here we demonstrate that uric acid induces triglyceride accumulation by SREBP-1c activation via induction of endoplasmic reticulum (ER) stress in hepatocytes. Uric acid-induced ER stress resulted in an increase of glucose-regulated protein (GRP78/94), splicing of the X-box-binding protein-1 (XBP-1), the phosphorylation of protein kinase RNA-like ER kinase (PERK), and eukaryotic translation initiation factor- $2 \alpha$ (elF-2 $\alpha$ ) in cultured hepatocytes. Uric acid promoted hepatic lipogenesis through overexpression of the lipogenic enzyme, acetyl-CoA carboxylase 1 (ACC1), fatty acid synthase (FAS), and stearoyl-CoA desaturase 1 (SCD1) via activation of SREBP-1C, which was blocked by probenecid, an organic anion transport blocker in HepG2 cells and primary hepatocytes. A blocker of ER stress, tauroursodeoxycholic acid (TUDCA), and an inhibitor of SREBP-1C, metformin, blocked hepatic fat accumulation, suggesting that uric acid promoted fat synthesis in hepatocytes via ER stress-induced activation of SREBP-1c. Uric acid-induced activation of NADPH oxidase preceded ER stress, which further induced mitochondrial ROS production in hepatocytes. These studies provide new insights into the mechanisms by which uric acid stimulates fat accumulation in the liver.

Laboratory Investigation (2014) 94, 1114-1125; doi:10.1038/labinvest.2014.98; published online 11 August 2014

The prevalence of non-alcoholic fatty liver disease (NAFLD) has increased rapidly, making it the most common cause of chronic liver disease in the developed world. ${ }^{1,2}$ Endoplasmic reticulum (ER) stress is now recognized as one of the mechanisms for fat accumulation in NAFLD. ${ }^{3}$ Disruption of ER homeostasis with activation of responsible signaling pathways and unfolded protein response (UPR) have been demonstrated in human cells and animal models of fatty liver. ${ }^{4-8}$ In addition, modulation of ER stress improved hepatic steatosis with a restoration of glucose homeostasis and insulin sensitivity in the diabetic mouse. ${ }^{9,10}$

A recent epidemiological study using data from the National Health and Nutrition Examination Survey revealed that uric acid was associated with NAFLD independently of metabolic syndrome. ${ }^{11}$ Additional studies have shown that elevated serum uric acid is an independent predictor of NAFLD. ${ }^{12}$ Recently, uric acid has been shown to have direct effects to increase hepatic fat accumulation via a mechanism involving the induction of mitochondrial oxidative stress, ${ }^{13}$ and lowering uric acid has been found to block hepatic fat accumulation in a variety of animal models. ${ }^{13-15}$ However, the role of ER stress in uric acidmediated hepatic fat accumulation has not been previously examined.

Fat accumulation in liver is associated with an enhanced expression of lipogenic genes, such as acetyl-CoA carboxylase 1 (ACC1), fatty acid synthase (FAS), and stearoyl-CoA desaturase 1 (SCD1), which can be regulated by several transcriptional factors including sterol regulatory element-binding

\footnotetext{
${ }^{1}$ Department of Internal Medicine, Ewha Womans University School of Medicine, Ewha Medical Research Center, Seoul, Republic of Korea; ${ }^{2}$ Department of Biochemistry, Ewha Womans University School of Medicine, Ewha Medical Research Center, Seoul, Republic of Korea; ${ }^{3}$ Department of Molecular Medicine, Ewha Womans University School of Medicine, Ewha Medical Research Center, Seoul, Republic of Korea; ${ }^{4}$ Department of Life Sciences, Division of Life and Pharmaceutical Sciences, Ewha Womans University, Seoul, Republic of Korea; ${ }^{5}$ College of Pharmacy and Research Institute of Pharmaceutical Sciences, Seoul National University, Seoul, Republic of Korea and ${ }^{6}$ The Division of Renal Diseases and Hypertension, University of Colorado Denver, Aurora, Colorado, USA

Correspondence: Dr D-H Kang, MD, PhD, Division of Nephrology, Ewha Womans University School of Medicine, Ewha Medical Research Center, 911 Mok-dong Yangcheon-Ku, Seoul 158-710, Korea and Professor E-S Oh, Division of Life and Pharmaceutical Sciences, Department of Life Sciences, Ewha Womans University, Daehyun-dong, Seodaemoon-Gu, Seoul 120-750, Korea.

E-mails: dhkang@ewha.ac.kr and OhES@ewha.ac.kr
}

Received 29 August 2013; revised 13 May 2014; accepted 10 June 2014 
protein (SREBP) and carbohydrate-response element-binding protein (ChREBP). ${ }^{16-20}$

In this study, we investigated whether uric acid induced ER stress in liver, and modulation of uric acid-induced ER stress could ameliorate hepatic fat accumulation. We also examined the differential activation of transcription factors responsible for uric acid-induced fat accumulation in hepatocytes with a demonstration of cross-talk between ER stress and oxidative stress.

\section{MATERIALS AND METHODS Reagents}

All chemicals and tissue plate were obtained from SigmaAldrich (St. Louis, MO) and NuncLabware (Waltham, MA) unless otherwise stated. Uric acid (Ultrapure, Sigma) was dissolved in warmed media and filtered before use.

\section{Cell Culture}

HepG2 cells (Korean Cell Line Bank of Seoul National University, Seoul, Korea) were maintained in RPMI 1640 medium (Thermo Scientific, Waltham, MA) supplemented with $10 \%$ fetal bovine serum, $100 \mathrm{U} / \mathrm{ml}$ penicillin and $100 \mu \mathrm{g} /$ $\mathrm{ml}$ streptomycin at $37{ }^{\circ} \mathrm{C}$ in a humidified $5 \% \mathrm{CO}_{2} / 95 \%$ air atmosphere incubator and exposed to different concentrations of uric acid $(0-12 \mathrm{mg} / \mathrm{dl})$.

\section{Isolation of Primary Mouse Hepatocytes}

Primary mouse hepatocytes were isolated by collagenase perfusion method.21,22 Briefly, mouse liver was perfused through portal vein using warm $\mathrm{Ca}^{2+}$ - and $\mathrm{Mg}^{2+}$-free Hank's balanced salt solution (Sigma-Aldrich) containing $5.5 \mathrm{mM} \mathrm{KCl}, 5.5 \mathrm{mM}$ glucose, $25 \mathrm{mM} \mathrm{NaHCO}$, and $0.7 \mathrm{mM}$ EDTA for 3 min and liver digest media (Invitrogen, Carlsbad, CA) for $8 \mathrm{~min}$. After perfusion, the liver was immediately collected and dissected using tweezers in $10 \mathrm{ml}$ of plating media (Dulbecco's modified Eagle's medium supplemented with $10 \%$ lipid-reduced fetal bovine serum, $2 \mathrm{mM}$ sodium pyruvate, $2 \%$ penicillin/streptomycin, $1 \mu \mathrm{M}$ dexamethasone, and $0.1 \mu \mathrm{M}$ insulin) and passed through a cell strainer $(70 \mu \mathrm{m}$ nylon mesh) (BD Falcon Labware, San Jose, CA). After centrifugation at $50 \mathrm{~g}\left(5 \mathrm{~min}, 4^{\circ} \mathrm{C}\right)$, the pellet was resuspended in $50 \%$ Percoll (Sigma-Aldrich) in plating medium. After centrifugation, the pellet was washed twice using plating medium, and then hepatocytes were seeded in collagencoated six-well plates.

\section{Intracellular Triglyceride (TG) Assay}

After an extraction of intracellular TG using 5\% NP-40 from HepG2 cells or primary mouse hepatocytes, TG content was measured with Triglyceride Quantification Kit (Abnova, Heidelberg, Germany). Intracellular TG was normalized by total protein content.

\section{Oil Red O Staining}

After an incubation of HepG2 cells or primary mouse hepatocytes with 3-12 mg/dl of uric acid for $48 \mathrm{~h}$, cells were washed with phosphate buffered saline (PBS) and fixed with $4 \%$ paraformaldehyde. Cells were stained with Oil Red O staining solution for $20 \mathrm{~min}$ at $60^{\circ} \mathrm{C}$ after an addition of $100 \%$ 1, 2-propanediol dehydration solution. The stained cells were photographed using phase-contrast microscope (Axiovert 200; Carl Zeiss, Oberkochen, Germany), and image was captured by a digital camera (AxioCam HRC; Carl Zeiss).

\section{Western Blotting Analysis}

HepG2 cells or primary mouse hepatocytes were lysed with RIPA buffer containing protease inhibitor cocktail (Roche Diagnostics, Mannheim, Germany). After denaturation and boiling of protein, lysates were loaded and resolved on $10 \%$ SDS-PAGE gels and transferred to a polyvinylidene difluoride membrane (Atto Corporation, Tokyo, Japan) for $2 \mathrm{~h}$ at $4{ }^{\circ} \mathrm{C}$. Membranes were incubated overnight with each primary antibodies at $4{ }^{\circ} \mathrm{C}$ : anti-ACC1 (Abcam, Cambridge, MA), anti-FAS (Santa Cruz Biotechnology, Santa Cruz, CA), antiSCD1 (Cell signaling, Danvers), anti- $\beta$-actin (Santa Cruz Biotechnology), anti-KDEL GRP78/94 (Enzo Life Sciences, Plymouth, PA), anti-p-PERK (Cell signaling), anti-PERK (Cell signaling), anti-p-eIF-2 $\alpha$ (Cell signaling), anti-eIF- $2 \alpha$ (Santa Cruz Biotechnology), anti-ChREBP (Novus Biologicals, Littleton, CO), anti-SREBP-1 (Santa Cruz Biotechnology), anti-Lamin B1 (Santa Cruz Biotechnology), anti-p47 $7^{\text {phox }}$ (Cell signaling), anti-p-p47 ${ }^{\text {phox }}$ (Cell signaling), and antip22 $2^{\text {phox }}$ (Santa Cruz Biotechnology). After washing the blots with PBS with Tween 20, the blots were incubated with horseradish peroxidase-conjugated secondary antibodies corresponding to each primary antibody. Signals were enhanced and detected using enhanced chemiluminescence detection (Santa Cruz Biotechnology).

\section{Quantitative Real-Time PCR Analysis}

After isolation of total RNA using TRIZOL reagent (Molecular Research Center, Inc, Cincinnati, $\mathrm{OH}$ ) and quantification by measuring optical density at $260 \mathrm{~nm}$, cDNA was synthesized by the QuantiTect Reverse Transcription kit (Qiagen, Courtaboeuf, France) according to the manufacturer's protocol. The first strand obtained was quantified by real-time quantitative PCR using a SYBR Green assay on the iCycler Optical System (Applied Biosystems, Foster City, CA). The PCR cycle conditions for human gene consisted of $95^{\circ} \mathrm{C}$ for $60 \mathrm{~s}, 55^{\circ} \mathrm{C}$ for $30 \mathrm{~s}$, and $60^{\circ} \mathrm{C}$ for $45 \mathrm{~s}$ followed by a 10 -min extension at $72{ }^{\circ} \mathrm{C}$ (40 cycles). PCR primers for each lipogenic enzymes were as follows: ACC1: sense, $5^{\prime}$-GAGGGAAGGGAATTAG AA- $3^{\prime}$, antisense, $5^{\prime}$-ATCACCCCAGGGAGATAC-3'; FAS: sense, $5^{\prime}$-GACGTCTGCAAGCCCAAGTA- ${ }^{\prime}$, antisense, $5^{\prime}$-CA TCGTCTCCACCAAAATGC-3'; SCD1: sense, 5'-GCAGGAC GATATCTCTAGCT-3', antisense, 5'-GTCTCCAACTTATCT 
CCTCCATTC- $3^{\prime}$; and $\beta$-actin: sense, $5^{\prime}$-TTCTGACCCATG CCCAC, antisense, $5^{\prime}$-ATGGATGATATCGCCGCGCTC- $3^{\prime}$.

\section{Reverse Transcriptase-PCR Analysis of XBP-1 Splicing}

The splicing of XBP-1 mRNA was detected by semiquantitative RT-PCR using primers specific for XBP-1, which detected both unspliced (424 bp) and spliced (398 bp) isoforms: sense, 5'-CTGGAAAGCAAGTGGTAGA-3', antisense, 5'-CTGGGT CCTTCTGGGTAGAC- $3^{\prime}$; and $\beta$-actin, sense, $5^{\prime}$-TTCTGACC CATGCCCACCAT- ${ }^{\prime}$, antisense, $5^{\prime}$-ATGGATGATATCGCCG CGCTC- $3^{\prime}$.

\section{Cell Morphology and Immunocytochemistry}

Cell morphology was analyzed under an inverted phasecontrast microscope (Axiovert 200; Carl Zeiss), and image was captured by a digital camera (AxioCam HRC; Carl Zeiss). For immunofluorescence staining, HepG2 cells or primary mouse hepatocytes were washed with PBS and fixed in $4 \%$ paraformaldehyde for $20 \mathrm{~min}$ at $25^{\circ} \mathrm{C}$. After treatment with $1 \%$ Triton X-100 for 15 min at $4{ }^{\circ} \mathrm{C}$, cells were incubated with primary antibody specific for SREBP-1 overnight at $4{ }^{\circ} \mathrm{C}$, followed by an incubation with goat anti-mouse IgG-FITC-conjugated secondary antibody (Santa Cruz Biotechnology) for $1 \mathrm{~h}$ at $25^{\circ} \mathrm{C}$ in the dark. The cover slides were mounted in Vectashield mounting media with DAPI (Vector laboratories Inc, Burlingame, CA), and cells were visualized using an Axiovert 200 fluorescence inverted phase-contrast objectives.

\section{Effect of Taurine-Conjugated Ursodeoxycholic Acid (TUDCA), Metformin, and Antioxidants on Uric Acid-Induced ER Stress in Fat Accumulation}

Effects of ER stress blocker, TUDCA $(300 \mu \mathrm{M}$, Tokyo Kasei, Tokyo, Japan), a blocker of SREBP-1c cleavage, metformin a

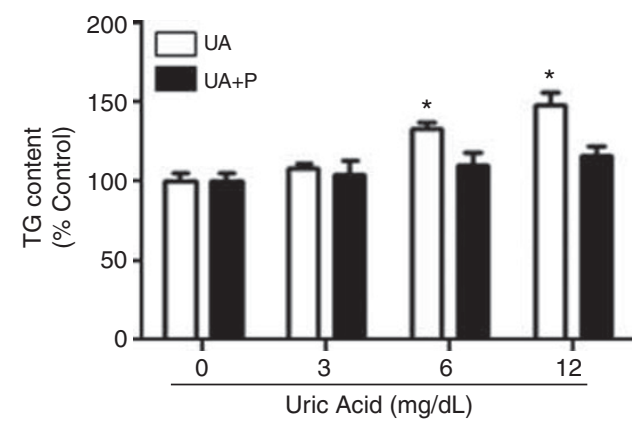

b
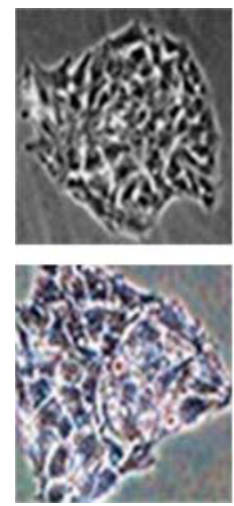

Control
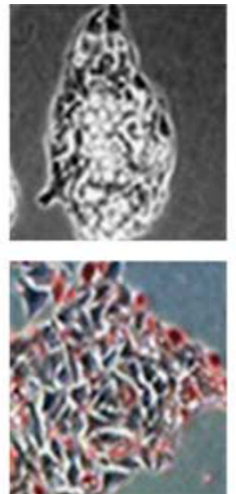

UA
C
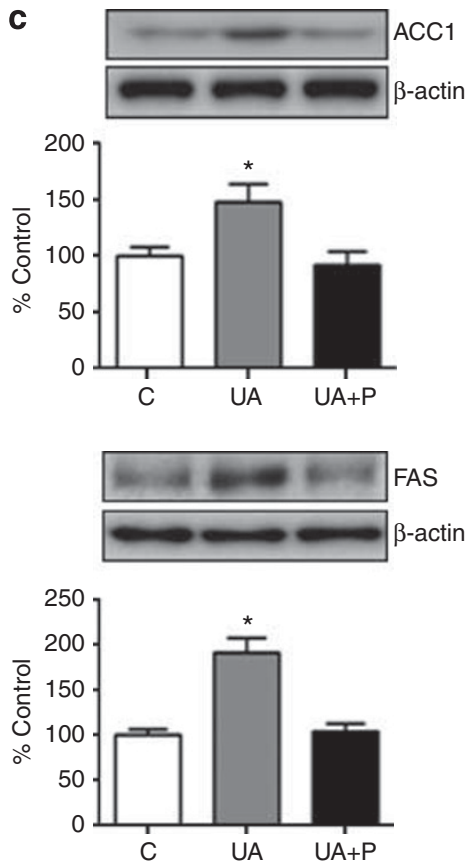

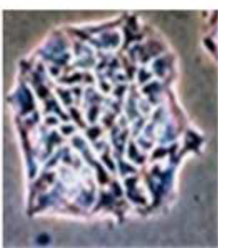

$U A+P$
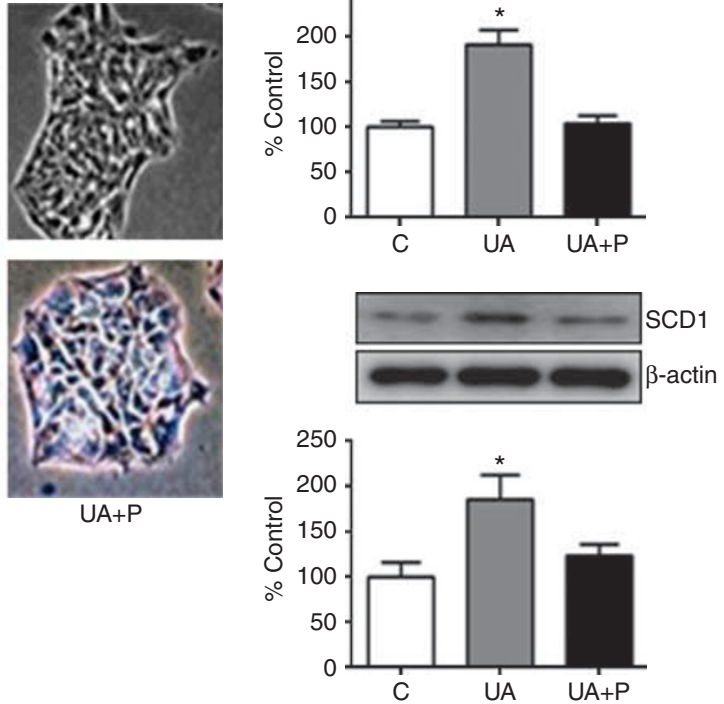

d
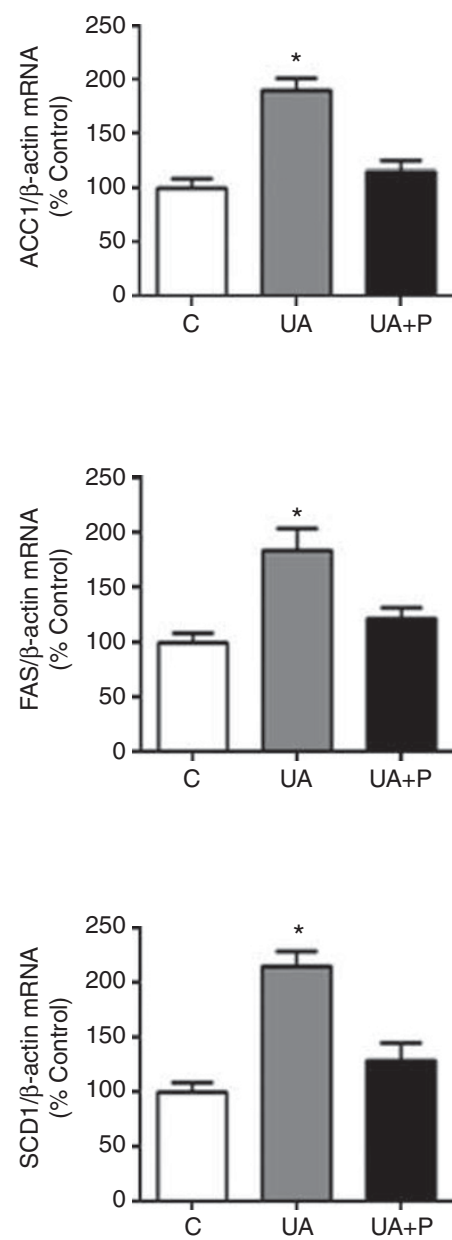

Figure 1 Effect of uric acid on TG accumulation and lipogenic enzymes expression in HepG2 cells. (a) Intracellular TG content in HepG2 cells is increased by uric acid (UA) from $6 \mathrm{mg} / \mathrm{dl}$ at $48 \mathrm{~h}$, which is ameliorated by probenecid $(\mathrm{P}, 0.5 \mathrm{mM})(n=5)$. ${ }^{*} P<0.05 \mathrm{vs} 0$ and $3 \mathrm{mg} / \mathrm{dl}$ of UA. (b) Phasecontrast microscope (upper row) and Oil Red O staining (lower row) reveal increased intracellular fat vacuoles in uric acid (12 mg/dl)-treated HepG2 cells at $48 \mathrm{~h}$, which is blocked by probenecid (P). Magnifications, $\times 200$. (c) Uric acid increases the protein levels of ACC1, FAS, and SCD1 in HepG2 cells at $24 \mathrm{~h}$ that are blocked by probenecid $(\mathrm{P})(n=6)$. (d) Uric acid also upregulates mRNA expression of lipogenic enzymes, which is ameliorated by probenecid $(\mathrm{P})$ at $12 \mathrm{~h}(n=6) .{ }^{*} P<0.05$ vs others. 
$(0.25 \mathrm{mM})$, and antioxidants, including $N$-acetyl cysteine (NAC, $2 \mathrm{mM}$ ), diphenyleneiodonium (DPI, $0.2 \mu \mathrm{M}$ ), and rotenone $(5 \mu \mathrm{M})$, on uric acid-induced changes in HepG2 cells were investigated.

\section{Measurement of NADPH Oxidase (NOX) Activity}

NOX activity was measured by the lucigenin-enhanced chemiluminescence method. After washing in ice-cold PBS and lysis of hepatocytes, cell homogenates $(100 \mu \mathrm{g})$ were added into $50 \mathrm{mM}$ PBS containing $1 \mathrm{mM}$ EGTA, $150 \mathrm{mM}$ sucrose, $5 \mu \mathrm{M}$ lucigenin as the electron acceptor, and $100 \mu \mathrm{M}$ NADPH as the donor. Superoxide production was expressed as the rate of relative chemiluminescence units per milligram of protein.

\section{Measurement of Hydrogen Peroxide Production}

Hydrogen peroxide $\left(\mathrm{H}_{2} \mathrm{O}_{2}\right)$ production was measured using Amplex Red Hydrogen Peroxide (Invitrogen). Briefly, HepG2 cells were incubated with $100 \mu \mathrm{M}$ Amplex Red (Invitrogen) after an exposure to uric acid (0-12 mg/dl). A serial fluorescence was measured using fluorescent ELISA reader at excitation $571 \mathrm{~nm}$ and emission $585 \mathrm{~nm}$ (Molecular Devices).

\section{Immunoprecipitation}

For immunoprecipitation, whole-cell extracts prepared with lysis buffer were incubated overnight with appropriate antibodies at $4{ }^{\circ} \mathrm{C}$, and immune complexes were trapped on protein A/G-sepharose beads for $4 \mathrm{~h}$ (Amersham, Buckinghamshire, England). Beads were washed five times with cold lysis buffer (50 mM Tris- $\mathrm{HCl}, \mathrm{pH} 7.5,150 \mathrm{mM} \mathrm{NaCl}$ ) containing $1 \times$ protease inhibitors (Roche Molecular). After denaturation and boiling of protein, lysates were loaded and resolved on 10\% SDS-PAGE gels and transferred to a polyvinylidene difluoride membrane (Atto Corporation, Tokyo, Japan) for $2 \mathrm{~h}$ at $4{ }^{\circ} \mathrm{C}$. Membranes were incubated overnight with each primary antibodies at $4{ }^{\circ} \mathrm{C}$ : anti-p $47^{\text {phox }}$ (Cell signaling) anti-p-p47 $7^{\text {phox }}$ (Cell signaling), and anti-p22 $22^{\text {phox }}$ (Santa Cruz Biotechnology). After washing the blots with PBS with Tween 20, the blots were incubated with horseradish peroxidase-conjugated secondary antibodies corresponding to each primary antibody. Signals were enhanced

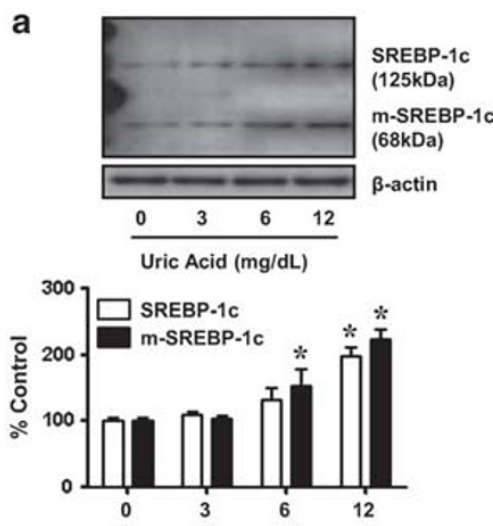

b
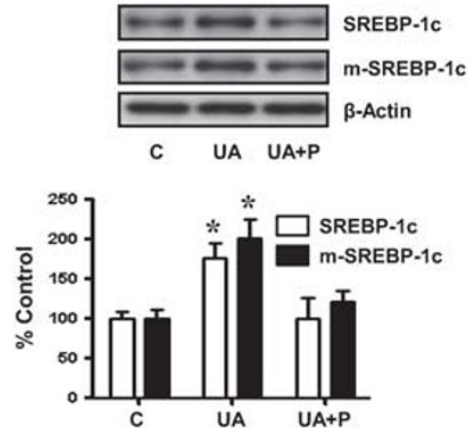

Cytoplasmic protein
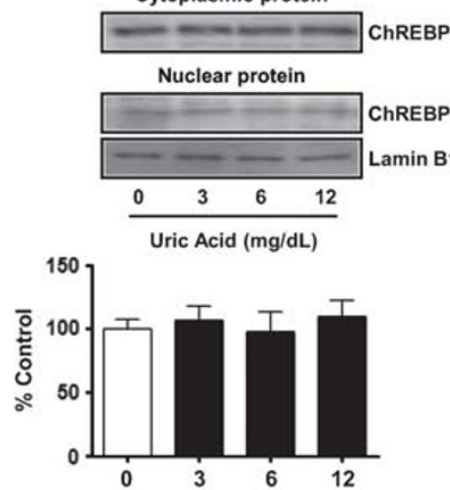

Cytoplasmic protein
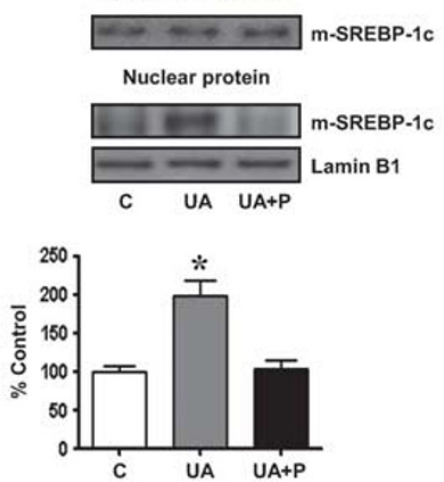

c

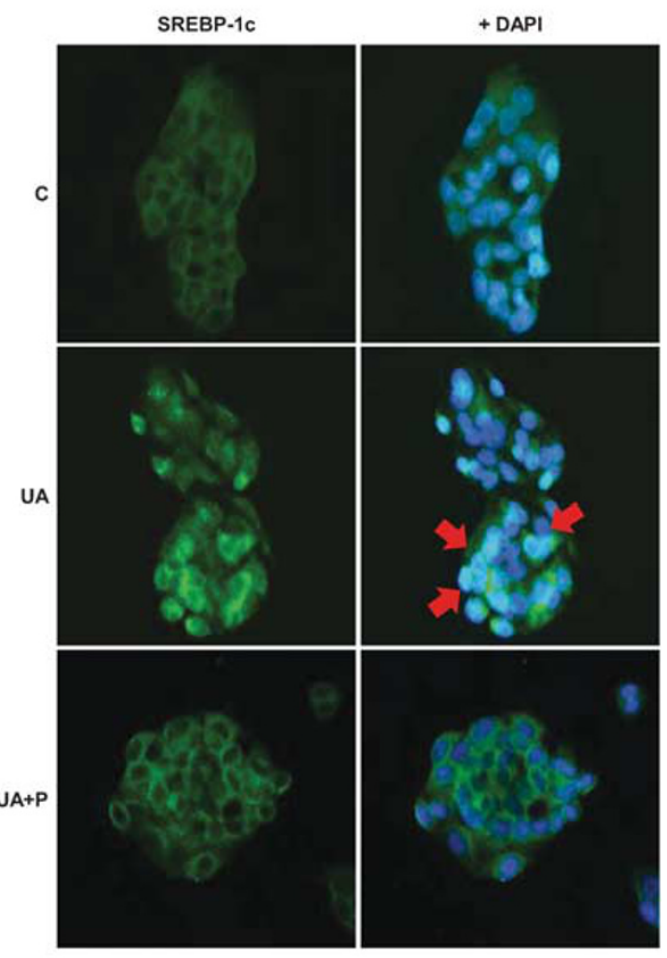

Figure 2 Effect of uric acid on transcription factors and SREBP-1c cleavage in HepG2 cells. (a) SREBP-1c (125 kDa) and m-SREBP-1c (mature form, $68 \mathrm{kDa}$ ) are increased by uric acid (UA) from 6 and $12 \mathrm{mg} / \mathrm{dl}$ at $24 \mathrm{~h}$, respectively; however, ChREBP protein expression in cytoplasmic and nuclear extract of HepG2 cells is not changed $(n=5)$. (b) Probenecid (P) blocks the effect of uric acid-associated increase in SREBP-1c and m-SREBP-1c expression at $24 \mathrm{~h}$. An enhanced expression of $\mathrm{m}$-SREBP-1c by uric acid is observed in nuclear extract of HepG2 cells. Quantitation bar is shown for nuclear m-SREBP-1c expression $(n=5)$. ${ }^{*} P<0.05$ vs others. (c) Fluorescence immunocytochemistry for SREBP-1c (green) reveals nuclear translocation of SREBP-1c by uric acid (yellow) that is generally localized in cell membrane and cytoplasm in control HepG2 cells. DAPI nuclear staining is seen in blue. Probenecid (P) ameliorates nuclear localization of SREBP-1 by uric acid. Magnification, $\times 200$. 
a
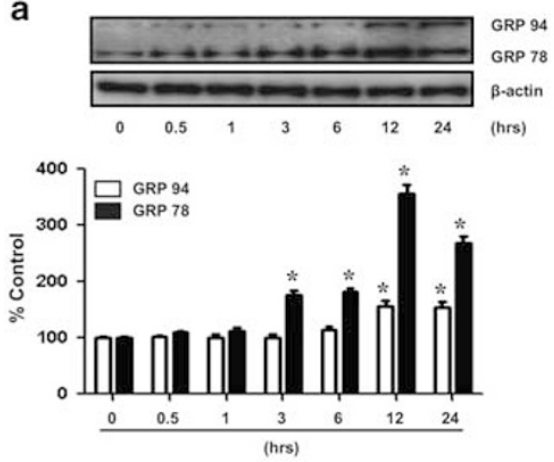

C
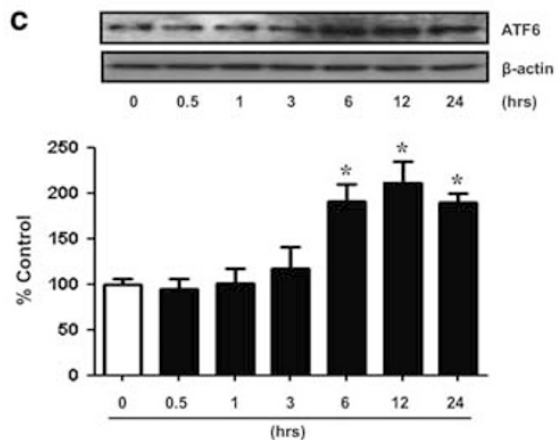

b
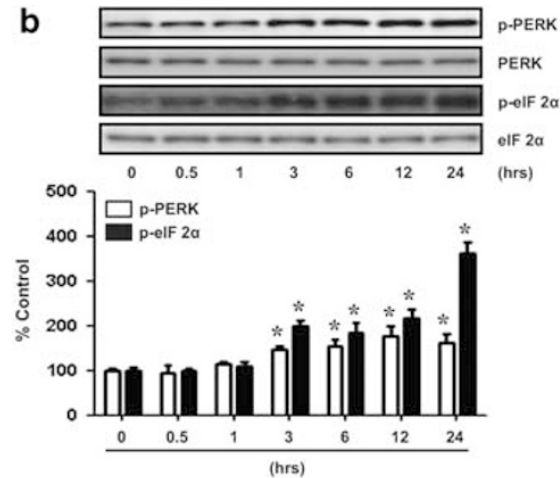

d
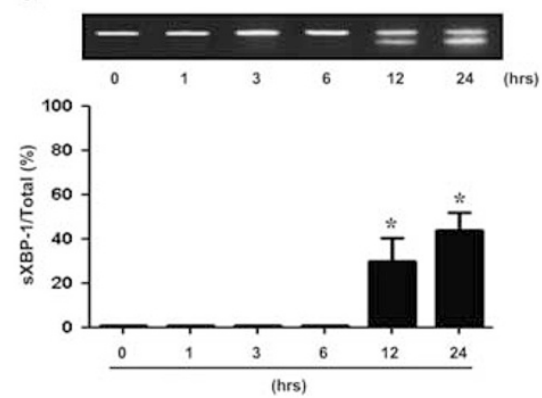

Figure 3 Effect of uric acid on ER stress in HepG2 cells. (a) Uric acid $(12 \mathrm{mg} / \mathrm{dl})$ increases the expression of GRP78/94 from $3 \mathrm{~h}(n=6)$. (b and $\mathbf{c})$ Uric acid activates the phosphorylation of PERK/elF- $2 \alpha$ and ATF6 expression from 3 and $6 \mathrm{~h}$, respectively $(n=6)$. (d) Uric acid also induces XBP-1 splicing from $12 \mathrm{~h}$. The PCR products of XBP-1 are shown as unspliced and spliced form XBP-1 $(n=5) .{ }^{*} P<0.05$ vs other time points.

a

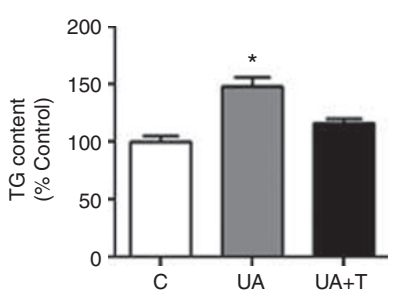

C b
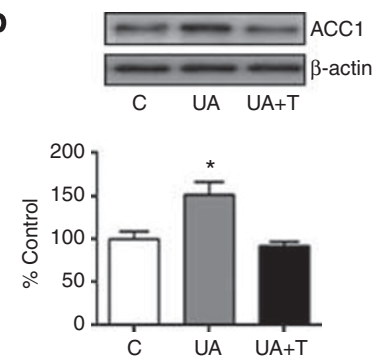
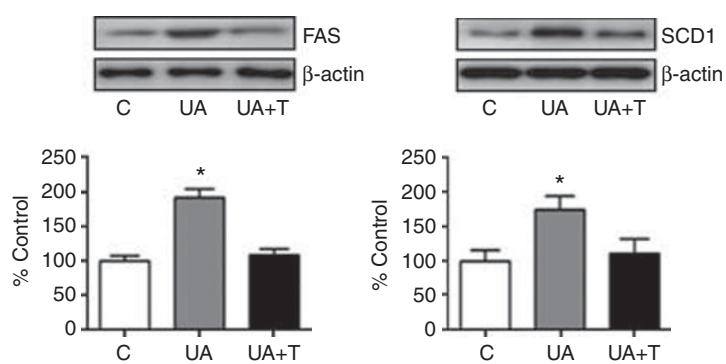

d

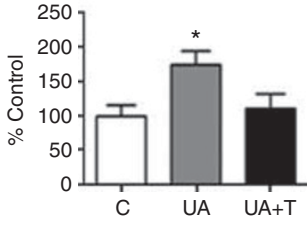

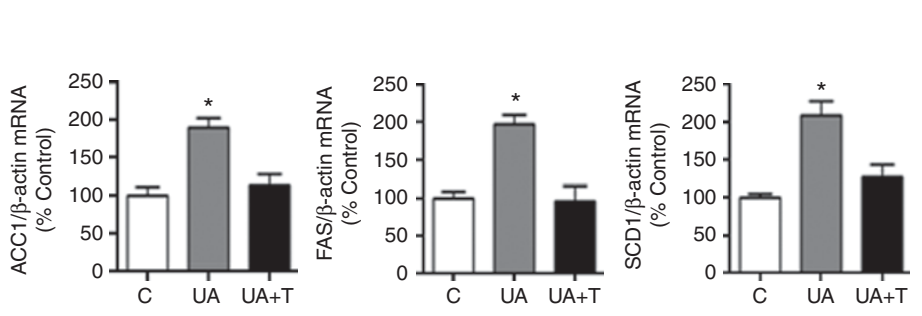

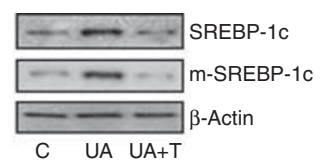

Cytoplasmic protein $\because m-N$ mEBP-1c \begin{tabular}{l} 
Nuclear protein \\
\hline
\end{tabular}
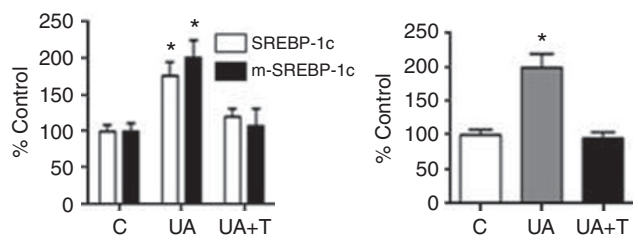

Figure 4 Effect of TUDCA on uric acid-induced TG accumulation, lipogenic enzymes, and SREBP-1c activation. (a) Uric acid (12 mg/dl)-induced fat accumulation is blocked by ER stress blocker, TUDCA $(\mathrm{T}, 300 \mu \mathrm{M})$ at $48 \mathrm{~h}(n=5)$. (b) TUDCA (T) blocks uric acid-induced increase in ACC1, FAS, and SCD1 proteins in HepG2 cells at $24 \mathrm{~h}(n=5)$. (c) Uric acid-induced mRNA expression of lipogenic enzymes is ameliorated by TUDCA ( $n=5)$. ${ }^{*} P<0.05$ vs others. (d) Uric acid-induced increase in SREBP-1c, m-SREBP-1c, and its nuclear translocation are blocked by TUDCA (T) at $24 \mathrm{~h}(n=5) .{ }^{*} P<0.05$ vs others. 
and detected using enhanced chemiluminescence detection (Santa Cruz Biotechnology).

\section{Detection of Mitochondrial Superoxide Levels}

Mitochondrial superoxide production was measured using MitoSOX (Invitrogen). Briefly, HepG2 cells were washed with PBS and then incubated in media containing MitoSOX Red $(2.5 \mu \mathrm{M})$ for $30 \mathrm{~min}$ at $37^{\circ} \mathrm{C}$ in dark conditions. Cells image was obtained using Axiovert 200 fluorescence microscope (Carl Zeiss).

\section{Statistical Analysis}

The results are presented as mean \pm s.d. and analyzed using $t$-test or one-way ANOVA (GraphPad Prism 5.0) followed by correction for multiple comparisons. The results were considered significant if the $P$-value was $<0.05$.

\section{RESULTS}

Uric acid-Induced TG Accumulation in HepG2 Cells with an Enhanced Expression of Lipogenic Enzymes

Uric acid increased the content of intracellular TG in HepG2 cells beginning at $6 \mathrm{mg} / \mathrm{dl}$ (Figure 1a). The organic anion transport blocker, probenecid, attenuated uric acid-induced intracellular TG accumulation, suggesting that uric acid requires entry into the cell to stimulate fat accumulation in HepG2 cells. The increased intracellular TG was also demonstrated by Oil Red $\mathrm{O}$ staining (Figure $1 \mathrm{~b}$ ). Uric acid induced endogenous lipogenic enzymes encoding ACC1, FAS, and SCD1, which was inhibited by coincubation with probenecid (Figures 1c and d).

\section{Uric Acid Induced Cleavage of SREBP-1c but did not Alter ChREBP Expression in HepG2 Cells}

Uric acid increased the endogenous protein levels of SREBP1c and m-SREBP-1c (mature form) in HepG2 cells; however, a

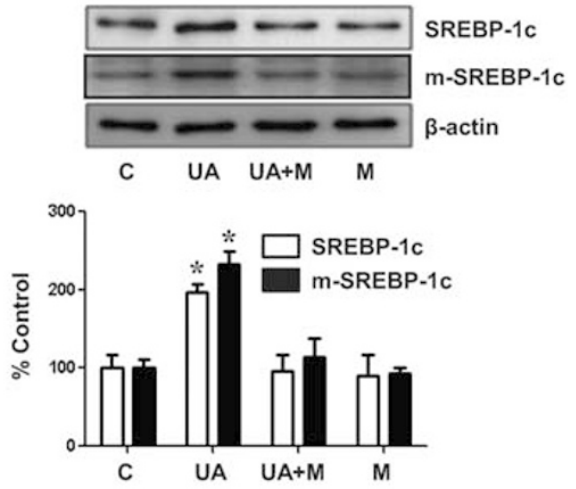

C
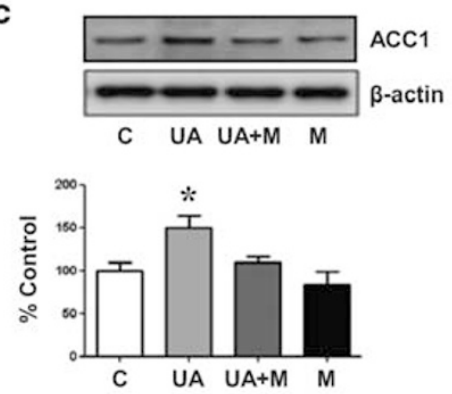

d

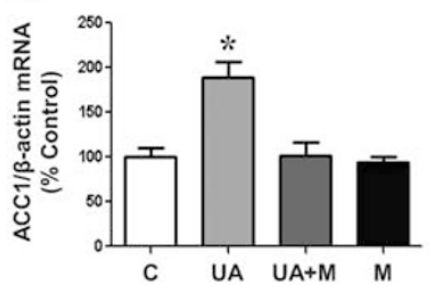

Cytoplasmic protein
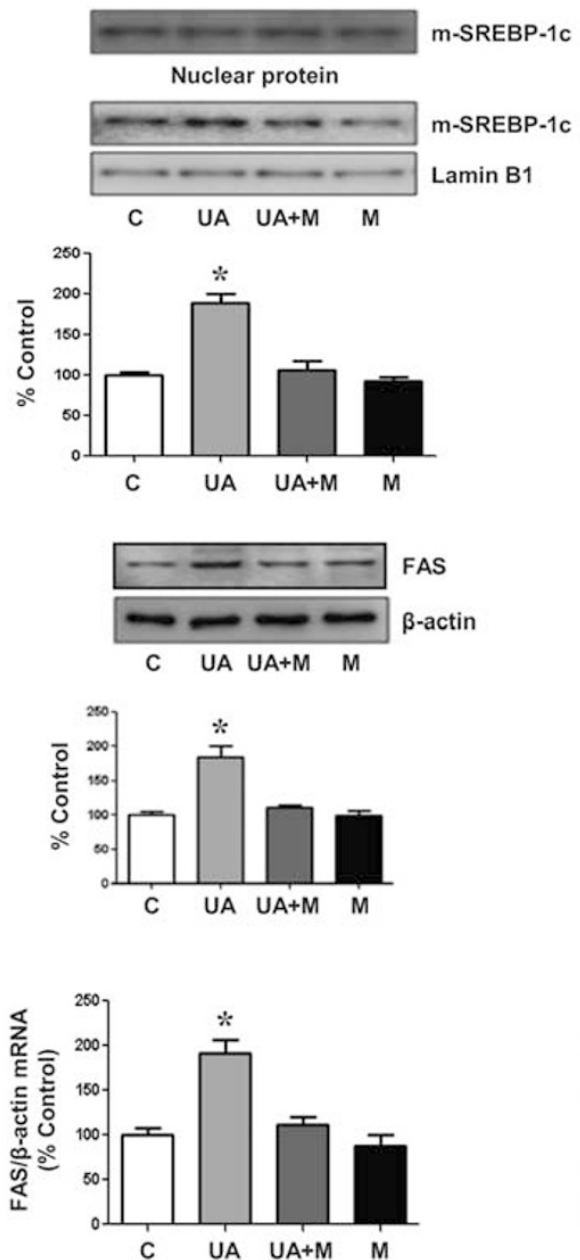

b
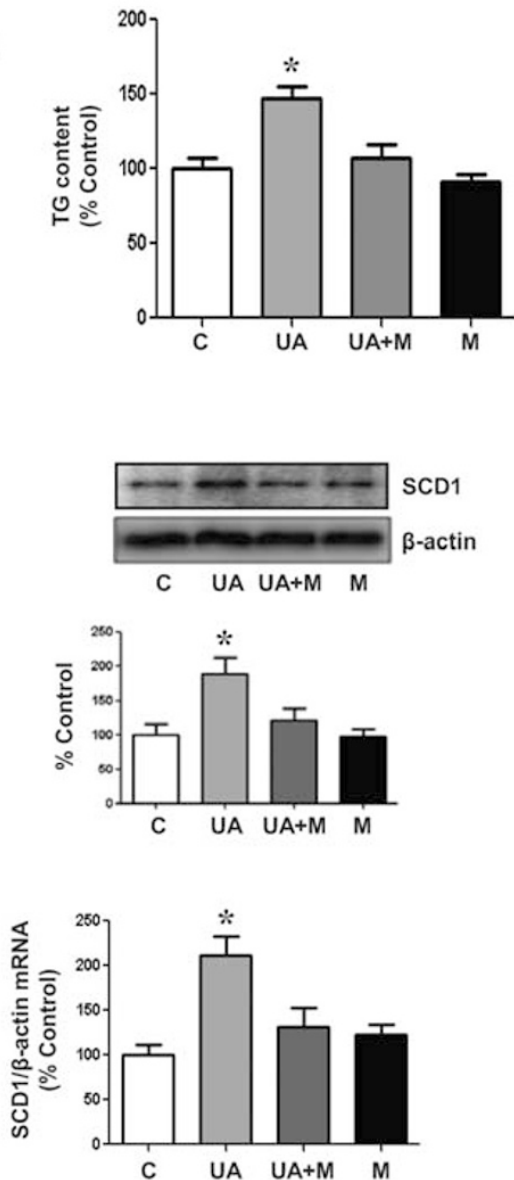

Figure 5 Effect of metformin on uric acid-induced SREBP-1c activation, fat accumulation, and the expression of lipogenic enzymes. (a) Uric acid $(12 \mathrm{mg} / \mathrm{dl})$-induced increase in SREBP-1c, m-SREBP-1c, and its nuclear translocation of $\mathrm{m}$-SREBP-1c are ameliorated by metformin $(\mathrm{M})$ at $24 \mathrm{~h}(n=5)$. ${ }^{*} P<0.05$ vs others. (b-d) Metformin (M) inhibits both hepatic TG accumulation at $48 \mathrm{~h}(n=5)$ and enhanced expression of ACC1, FAS, and SCD1 by uric acid (UA) at $24 \mathrm{~h}(n=5)$. Representative western blots with quantitation of protein (c) and mRNA (d) are shown. ${ }^{*} P<0.05$ vs others. 
the expression of ChREBP protein was comparable in control and uric acid-treated cells (Figure 2a). Probenecid significantly inhibited the effect of uric acid on m-SREBP-1c level (Figure 2b). An enhanced expression of m-SREBP-1c by uric acid was seen in nuclear extract of HepG2 cells, but not in cytoplasmic protein. Translocation of m-SREBP-1c into
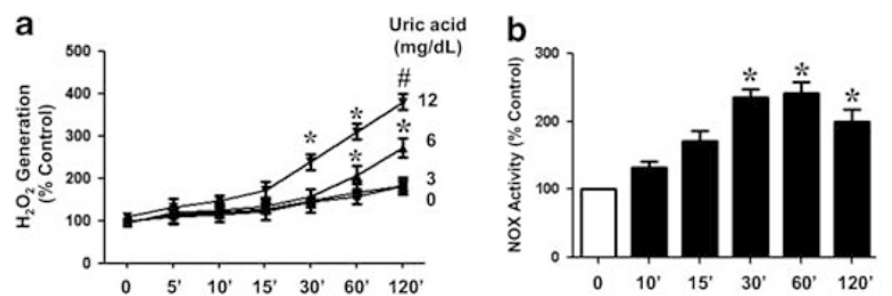

C
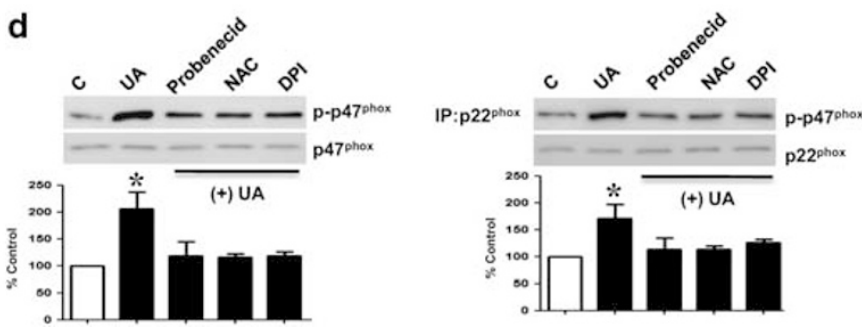

Figure 6 Effect of uric acid on $\mathrm{H}_{2} \mathrm{O}_{2}$ production in $\mathrm{HepG} 2$ cells and effect of antioxidants on uric acid-induced TG accumulation and p-p47 ${ }^{\text {phox }}$ and $\mathrm{p}-\mathrm{p} 47^{\text {phox }}-\mathrm{p} 22^{\text {phox }}$ interaction. (a and b) Uric acid $\left(>6 \mathrm{mg} / \mathrm{dl}\right.$ ) increases ROS generation from 30 min as assessed by $\mathrm{H}_{2} \mathrm{O}_{2}$ staining, with an increase in NOX activity $(n=3)$. ${ }^{*} P<0.05$ vs other time points at each concentration of uric acid, $\# P<0.05$ vs other concentration of uric acid at 120 min. (c) Uric acid-induced TG accumulation in HepG2 cells at $48 \mathrm{~h}$ is ameliorated by antioxidants, including NAC, DPI, and rotenone $(n=4) .{ }^{*} P<0.05$ vs others. (d) Uric acid-induced $\mathrm{p}-\mathrm{p} 47^{\text {phox }}$ and interaction of $\mathrm{p}-\mathrm{p} 47^{\text {phox }}$ with $\mathrm{p} 22^{\text {phox }}$ in HepG2 cells are ameliorated by probenecid (P), NAC, and DPI $(n=4) .{ }^{*} P<0.05$ vs others.

a
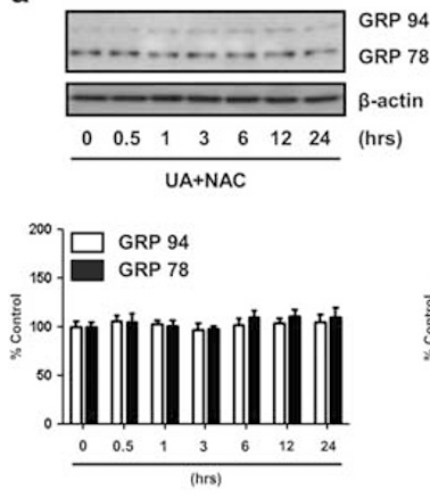

C
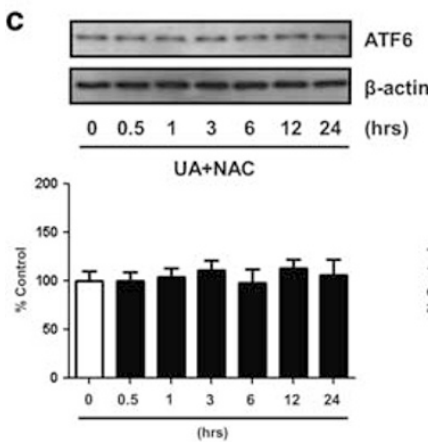
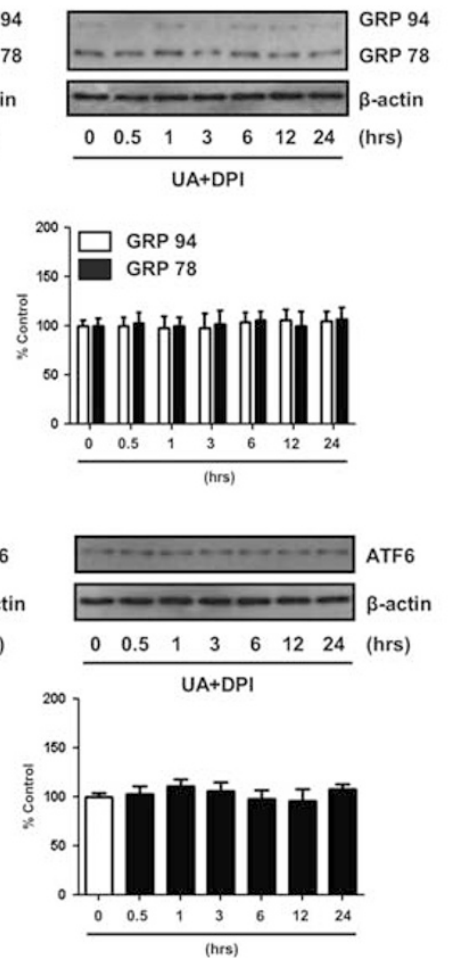

b
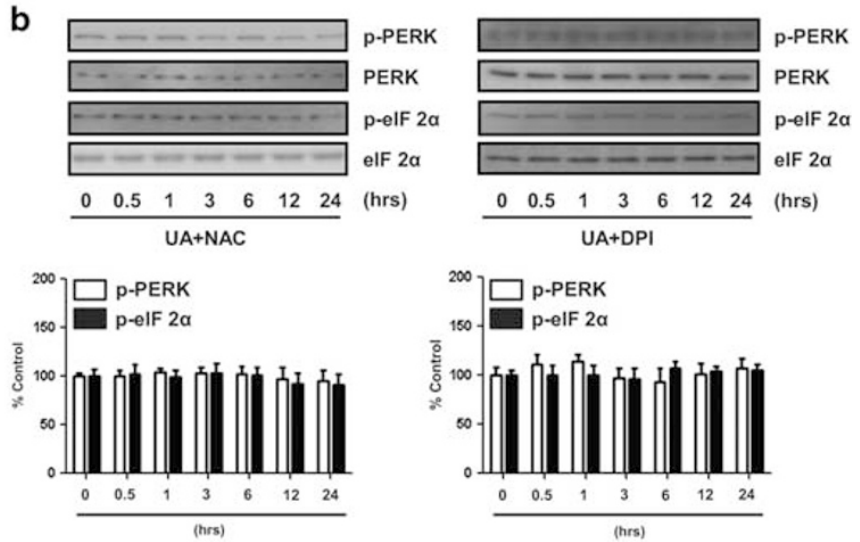

d
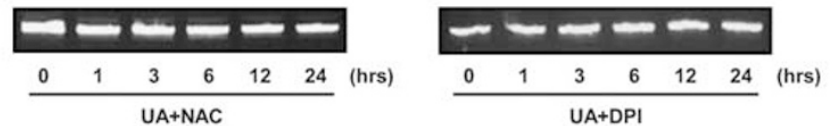

Figure 7 Effect of NAC and DPI on uric acid-induced ER stress in HepG2 cells. (a) NAC ( $2 \mathrm{mM})$ and DPI (0.2 $\mu$ M) significantly inhibit uric acid (12 mg/dl)induced GRP78/94 expression ( $n=5$ ). (b and $\mathbf{c}$ ) NAC and DPI significantly inhibit the phosphorylation of PERK/elF-2 $\alpha$ and ATF6 level induced by uric acid in HepG2 cells $(n=5)$. (d) Uric acid-induced XBP-1 splicing is also blocked by NAC and DPI $(n=5)$. 
the nucleus was also confirmed by immunocytochemistry (Figure 2c).

\section{Uric Acid Induced ER Stress in HepG2 Cells}

Uric acid $(12 \mathrm{mg} / \mathrm{dl})$ induced an increased expression of GRP78/94 in HepG2 cells in a time-dependent manner (Figure 3a). Uric acid induced the phosphorylation of PERK and eIF- $2 \alpha$ (Figure $3 b$ ) and the expression of ATF6 (Figure 3c). XBP-1 mRNA spicing, which was known to be induced by activation of IRE-1 endoribonuclease of IRE-1dependent pathway of ER stress, ${ }^{23}$ was also observed in uric acid-treated HepG2 cells (Figure 3d).

\section{Blocking of ER Stress Ameliorated Uric Acid-Induced TG Accumulation and the Increase in ACC1, FAS, and SCD1 in HepG2 Cells}

TUDCA ameliorated uric acid-induced fat accumulation (Figure 4a) as well as induction of lipogenic enzymes, ACC1, FAS, and SCD1 (Figures $4 \mathrm{~b}$ and c). TUDCA also inhibited the expression of $\mathrm{m}$-SREBP-1c and nuclear translocation of m-SREBP-1c in HepG2 cells (Figure 4d).

a
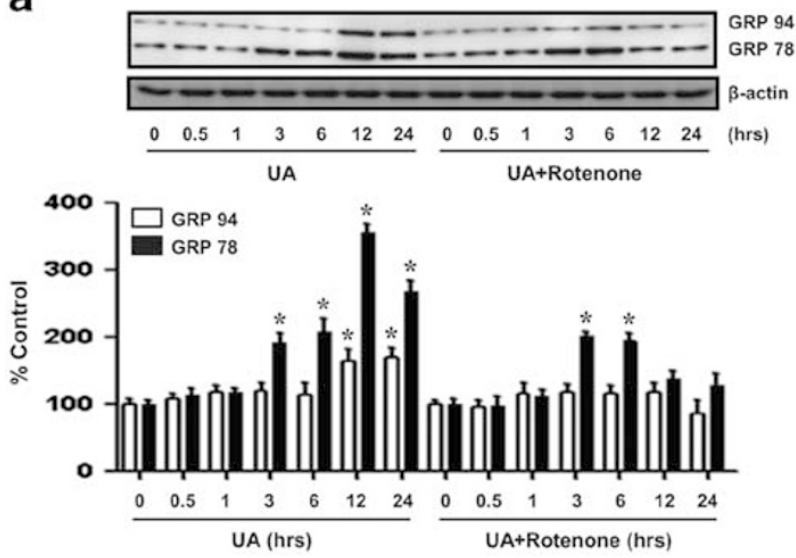

C
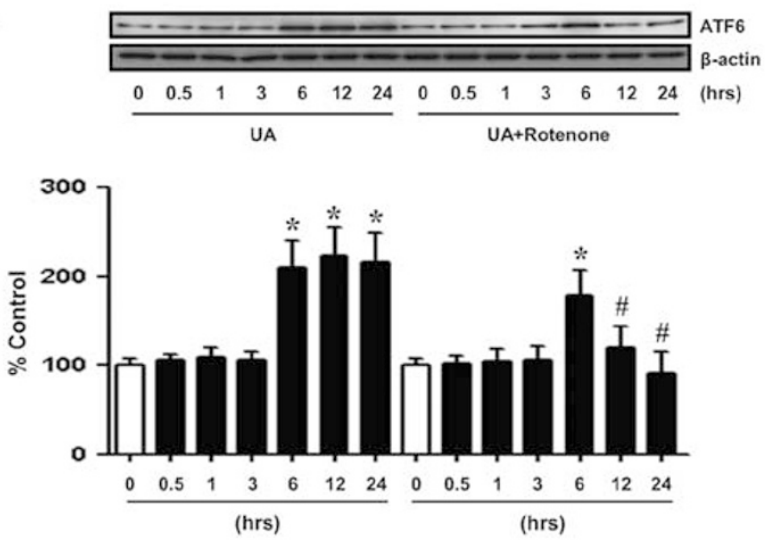

SREBP-1c Cleavage and Nuclear Translocation were Responsible for Uric Acid-Induced Fat Accumulation and the Overexpression of ACC1, FAS, and SCD1

In order to examine whether SREBP-1c cleavage and nuclear translocation were responsible for uric acid-induced fat accumulation, we investigated the effect of metformin, an antidiabetic drug which was known to block SREBP-1c cleavage and nuclear translocation. ${ }^{24}$ Metformin blocked uric acidinduced SREBP-1c cleavage and nuclear translocation (Figure 5a). Uric acid-induced fat accumulation as well as induction of lipogenic enzymes was also ameliorated by metformin (Figures $5 \mathrm{~b}-\mathrm{d}$ ), consistent with the hypothesis that SREBP-1c cleavage might contribute to uric acid-induced fat deposition in hepatocytes.

\section{Uric Acid-Induced Oxidative Stress Preceded ER Stress in Hepatocyte}

Previously, we demonstrated uric acid-induced oxidative stress as a major mechanism of fat accumulation in HepG2 cells. ${ }^{13}$ Uric acid ( $>6 \mathrm{mg} / \mathrm{dl}$ ) increased $\mathrm{H}_{2} \mathrm{O}_{2}$ production and NOX activity in HepG2 cells from 30 min (Figures $6 a$ and b).
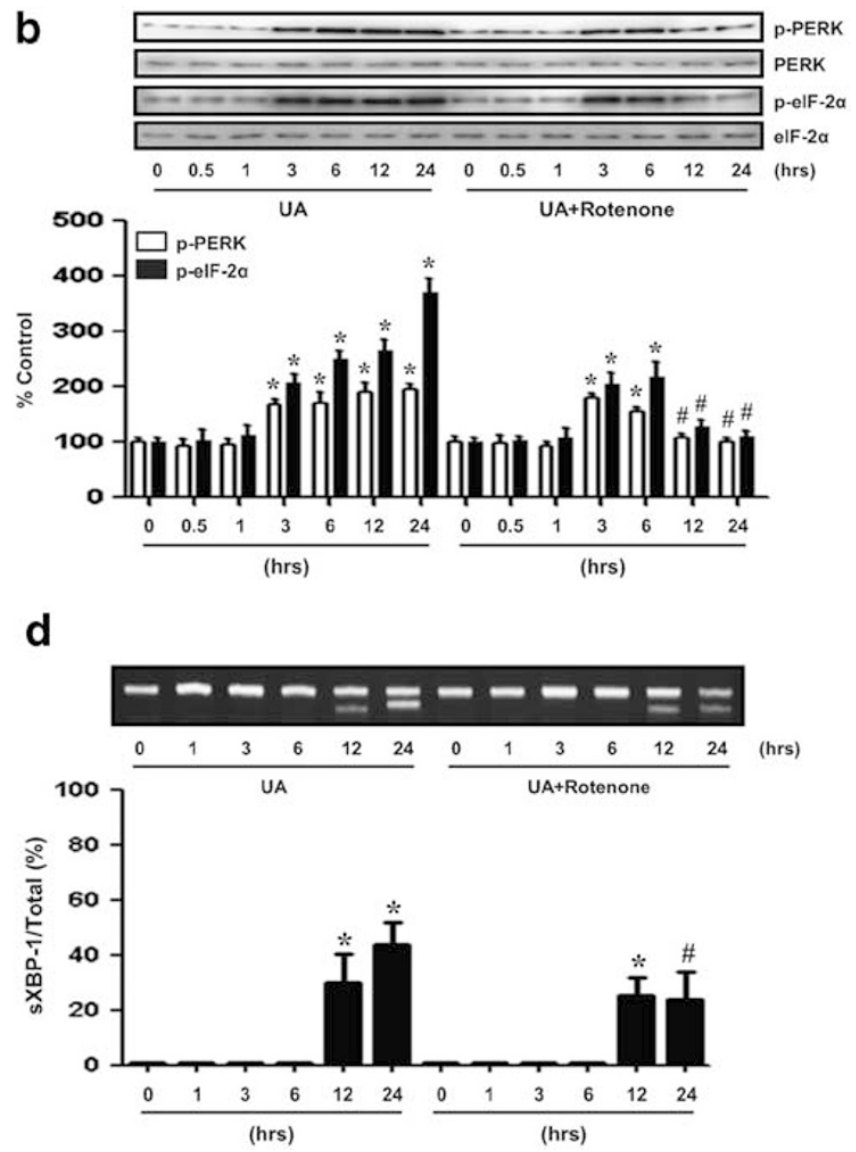

Figure 8 Effect of rotenone on uric acid-induced ER stress in HepG2 cells. (a) Rotenone ( $5 \mu \mathrm{M})$ does not alter GRP78/94 expression at 3 and $6 \mathrm{~h}$ of uric acid stimulation; however, it blocks GRP78/94 from $12 \mathrm{~h}(n=5)$. (b and $\mathbf{c})$ Rotenone ameliorates the phosphorylation of PERK/elF-2 $\alpha$ and ATF6 level at 12 and $24 \mathrm{~h}$ of uric acid stimulation despite no significant effect on uric acid-induced phosphorylation at 3 or $6 \mathrm{~h}(n=5)$. ${ }^{*} P<0.05$ vs other time points, ${ }^{\#} P<0.05$ vs UA at 12 or $24 \mathrm{~h}$. (d) Rotenone also alleviates uric acid-induced XBP-1 splicing at $24 \mathrm{~h}(n=5) .{ }^{*} P<0.05$ vs other time points for each condition, ${ }^{\#} P<0.05$ vs UA at $24 \mathrm{~h}$. 
Antioxidants, including NAC, DPI, and rotenone, blocked TG accumulation in HepG2 cells (Figure 6c), suggesting both NOX-dependent and mitochondria-mediated oxidative stress generated by uric acid were responsible for hepatic fat accumulation.

To investigate the mechanism of uric acid-induced increase in NOX activity, we examined the phosphorylation of $\mathrm{p} 47^{\text {phox }}$ $\left(\mathrm{p}-\mathrm{p} 47^{\text {phox }}\right)$ and $\mathrm{p}-\mathrm{p} 47^{\text {phox }}-\mathrm{p} 22^{\text {phox }}$ interaction. Uric acid increased $\mathrm{p}-\mathrm{p} 47^{\mathrm{phox}}$ and $\mathrm{p}-\mathrm{p} 47^{\text {phox }}-\mathrm{p} 22^{\text {phox }}$ interaction, which were blocked by probenecid, NAC, and DPI (Figure 6d).

Interestingly, pretreatment with NAC or DPI blocked uric acid-induced ER stress in HepG2 cells (Figure 7). An inhibitor of mitochondrial complex I, rotenone, partially blocked uric acid-induced ER stress in HepG2 cells at later time points (Figure 8). TUDCA ameliorated mitochondrial ROS production in uric acid-exposed hepatocytes, suggesting that ER stress preceded mitochondrial ROS production in uric acid-stimulated hepatocytes although mitochondrial ROS stimulated UPR and TG accumulation at later time points. NAC and DPI also decreased mitochondrial ROS production (Figure 9).

\section{Uric Acid also Induced TG Accumulation and SREBP-1c Cleavage with Induction of ER Stress in Primary Hepatocytes}

To confirm whether uric acid also induced fat accumulation in primary hepatocytes, we measured TG content and the expression of SREBP and ChREBP in primarily isolated hepatocytes from mice. Uric acid increased the content of intracellular TG in primary mouse hepatocyte from $6 \mathrm{mg} / \mathrm{dl}$, which was blocked by probenecid (Figure 10a). The increased intracellular TG was also demonstrated by Oil Red O staining (Figure 10b). Uric acid also increased the expression of SREBP-1c and $\mathrm{m}$-SREBP-1c in primary mouse hepatocyte; however, it did not alter ChREBP expression (Figure 10c). Probenecid significantly inhibited the effect of uric acid on the expression of m-SREBP-1c in nuclear extracts of primary hepatocytes (Figure 10d). Uric acid enhanced the expression of GRP78/94 in primary hepatocytes at 12 and $24 \mathrm{~h}$, which was also blocked by probenecid (Figure 10e).

\section{DISCUSSION}

Hyperuricemia is prevalent in subjects with NAFLD and metabolic syndrome, although its clinical implication is still controversial. ${ }^{11,12}$ Recent experimental studies have reported a benefit of hypouricemic therapy in ameliorating fat deposition in liver, ${ }^{13-15}$ suggesting an etiological contribution of uric acid in the development of NAFLD or metabolic syndrome. In this study, we have demonstrated uric acidinduced fat accumulation in hepatocytes by enhancing the expression of lipogenic enzymes, which was associated with ER stress-mediated SREBP-1c cleavage and nuclear translocation. Importantly, ROS generation by NOX preceded the UPR that triggered mitochondrial ROS production in these

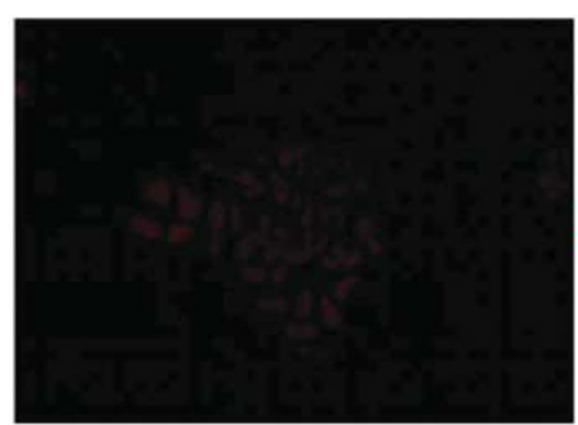

Control

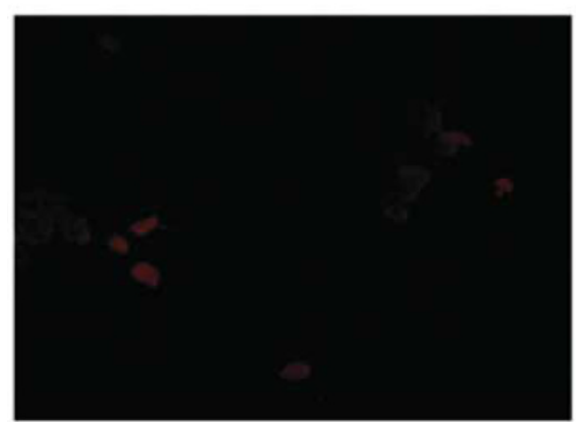

Uric Acid+NAC

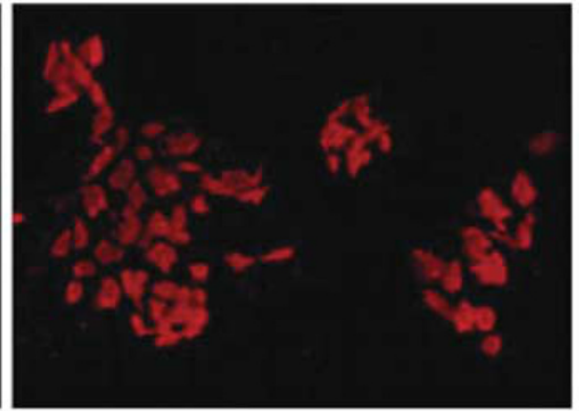

Uric Acid

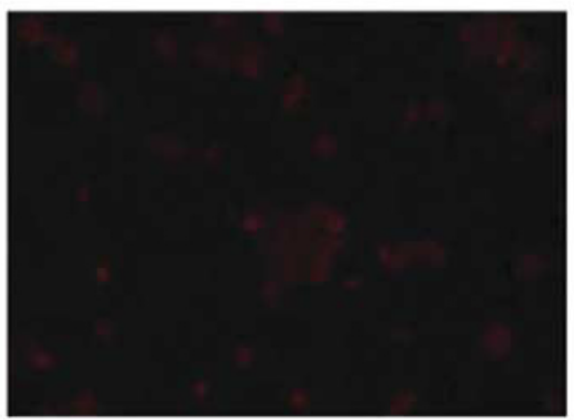

Uric Acid+DPI

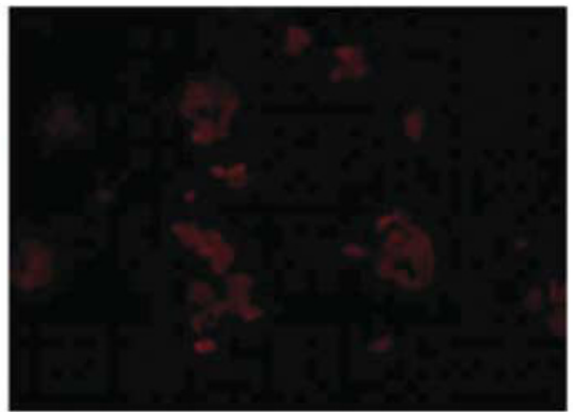

Uric Acid+TUDCA

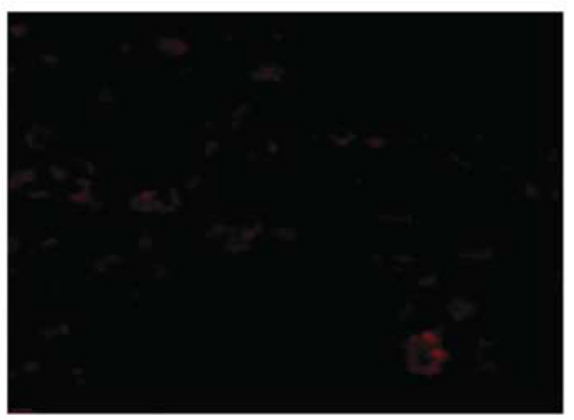

Uric Acid+Rotenone

Figure 9 Effect of TUDCA and antioxidants on uric acid-induced mitochondria ROS in HepG2 cells. Uric acid induces mitochondrial ROS production as assessed by Mito-SOX staining from $6 \mathrm{~h}$ of uric acid treatment $(n=4)$. Co-treatment with TUDCA, NAC, and DPI significantly reduces mitochondria oxidative stress in HepG2 cells exposed to uric acid $(12 \mathrm{mg} / \mathrm{dl})$. 
a

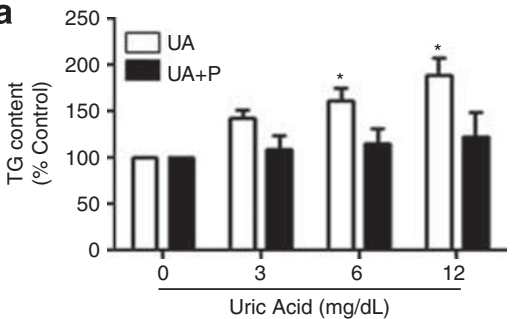

b

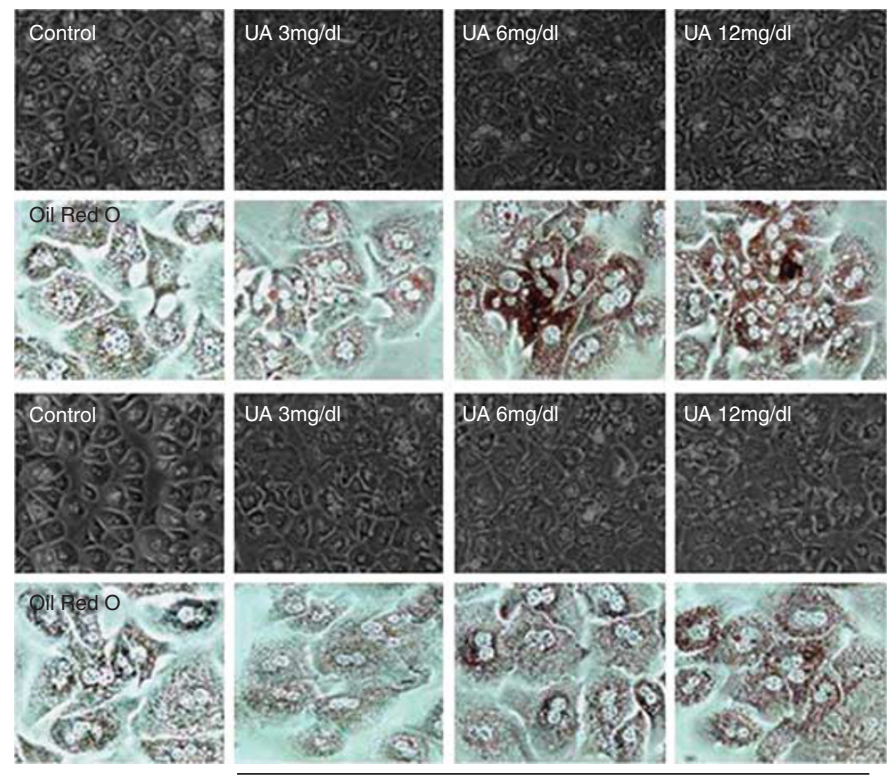

(+) Probenecid
C

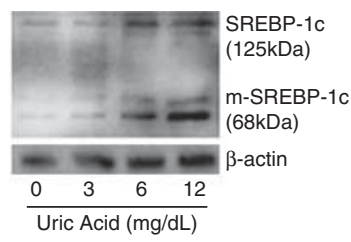

Cytoplasmic protein

- - - ChREBP

Nuclear protein

$-\cdots$ ChREBP

$---\frac{-}{0}-$ Lamin B1 \begin{tabular}{llll}
0 & 3 & 6 & 12 \\
\hline
\end{tabular}
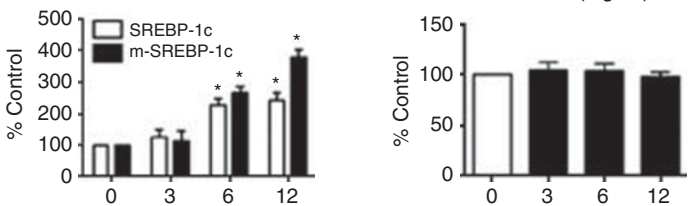

d

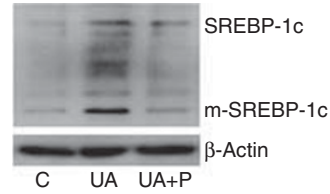

Cytoplasmic protein

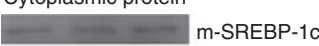

Nuclear protein

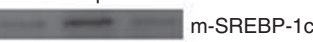

Lamin B

C UA UA+P
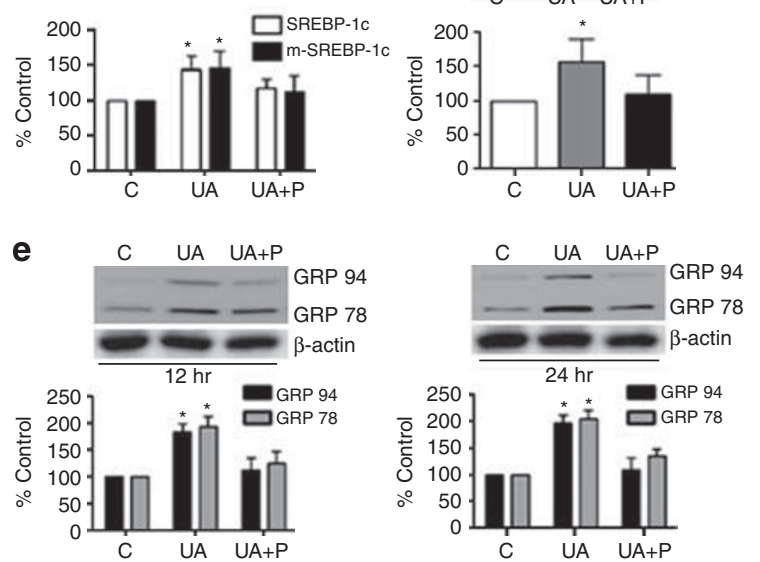

Figure 10 Effect of uric acid on TG accumulation, SREBP-1c cleavage and GRP expression in primary mouse hepatocyte. (a) Intracellular TG content in primary mouse hepatocyte is increased by uric acid (UA) from $6 \mathrm{mg} / \mathrm{dl}$ at $48 \mathrm{~h}$, which is ameliorated by probenecid $(0.5 \mathrm{mM}, \mathrm{P})(n=3)$. ${ }^{*} P<0.05 \mathrm{vs} 0$ and $3 \mathrm{mg} / \mathrm{dl}$ of uric acid. (b) Phase-contrast microscopy and Oil Red O staining reveal an increased fat vacuoles in uric acid-treated hepatocytes. (c) SREBP-1c (125 kDa) and m-SREBP-1c ( $68 \mathrm{kDa}$ ) are increased by uric acid ( $>6 \mathrm{mg} / \mathrm{dl})$ at 24 h; however, ChREBP protein expression in cytoplasmic and nuclear extract of primary mouse hepatocyte is not changed $(n=3)$. ${ }^{*} P<0.05$ vs 0 and 3 mg/dl of uric acid (d). Probenecid (P) blocks uric acidassociated increase in m-SREBP-1c expression and nuclear translocation at $24 \mathrm{~h}$ in primary mouse hepatocyte ( $n=3$ ). ${ }^{*} P<0.05$ vs control (C) and $\mathrm{UA}+\mathrm{P}$. (e) Uric acid increases GRP78/94 expression at 12 and $24 \mathrm{~h}$, which is ameliorated by probenecid $(\mathrm{P})(n=3)$. ${ }^{*} P<0.05$ vs control $(\mathrm{C})$ and $\mathrm{UA}+\mathrm{P}$. Representative western blots with quantitation of protein are shown.

cells. We have previously reported mitochondrial oxidative stress by uric acid-activated ATP citrate lyase and FAS that led to de novo lipogenesis in liver. ${ }^{13}$ In this manuscript, we have identified an additional mechanism whereby uric acid induces hepatic steatosis via ER stress.

One of the most important findings of this study was a demonstration of uric acid-induced fat accumulation in hepatocyte via induction of ER stress, which was confirmed in both HepG2 cells and primary mouse hepatocytes. We have demonstrated uric acid-induced ER stress in hepatocytes for the first time. ER is the site of protein folding and synthesis of lipid and sterols. ${ }^{7}$ As a protein-folding compartment, ER is exquisitely sensitive to alteration in homeostasis and provides stringent quality control to ensure the production of mature and correctly folded protein. With a perturbation of ER homeostasis and an accumulation of misfolded or unfolded protein, highly specific signaling pathways called UPR are activated to alleviate this stressful condition. The UPR is orchestrated by transcriptional activation of multiple genes through IRE-1 and ATF6. XBP-1 protein derived from IRE-1 and ATF6 transcription factors binds the ER stress response element and activates UPR-inducible genes, such as Bip, GRP94, and calreticulin. Recent studies showed that ER stress and UPR signaling is involved in regulating hepatic lipid metabolism and the development of NAFLD. ${ }^{3}$ The UPR branches through IRE-1/XBP-1 regulate the expression of lipogenic enzymes ${ }^{25}$ and the pathway through PERK/eIF- $2 \alpha$ was required for the development of fatty liver. ${ }^{5}$ Our data demonstrated that uric acid induced the expression of GRP78/94, ATF6, splicing of XBP-1, and phosphorylation 
of eIF- $2 \alpha$, which was activated by phospho-PERK in HepG2 cells. Probenecid, which blocks the entry of uric acid into cells, inhibited the activation of ER stress-related markers. Importantly, TUDCA, a bile acid derivative which was used as a chemical chaperon to enhance protein folding against ER stress, ${ }^{9,10}$ ameliorated uric acid-induced fat accumulation with an alleviation of ER stress. This finding suggested uric acid-induced ER stress played a role in hepatic steatosis.

Next, we investigated the mechanism of uric acid-induced fat accumulation mediated by ER stress. Uric acid enhanced the expression of three key lipogenic enzymes, including ACC1, FAS, and SCD1, which were also ameliorated by TUDCA. The gene expression of these lipogenic enzymes is known to be mainly regulated by two transcriptional factors, SREBP-1c and ChREBP. ${ }^{26,27}$ ChREBP is a glucose-responsive basic/helix-loop-helix/leucine zipper transcription factor that is mainly expressed in liver and specifically binds to a carbohydrate response element containing E box. Activation of ChREBP was reported to occur with fructose, which could be mediated by fructose-induced uric acid generation; ${ }^{13}$ however, we were not able to show a direct activation of ChREBP by uric acid. Despite an absence of uric acidinduced activation of ChREBP, our study showed that uric acid increased the cleavage of SREBP-1 into mature form and nuclear translocation. Upregulation of lipogenic enzymes and SREBP-1 is observed in both HepG2 cells and primary hepatocytes in this study.

To examine whether uric acid-induced cleavage of SREBP$1 c$ is a major pathway of fat accumulation in HepG2 cells, we used metformin, an anti-diabetic drug that is known to phosphorylate SREBP-1c and block the cleavage and nuclear translocation of SREBP-1c. Metformin significantly blocked uric acid-induced TG accumulation and induction of lipogenic enzymes.

We also demonstrated cross-talk between oxidative stress and ER stress. We have previously reported that uric acid induces oxidative stress in glomerular cell, adipocyte, and hepatocyte by increasing NOX activity. ${ }^{13,28,29}$ Oxidative stress in uric acid-stimulated HepG2 cells was especially linked with NOX4 activation and mitochondrial dysfunction evidenced by the effect of NOX4 siRNA on uric acid-induced TG accumulation in HepG2 cells. In this experiment, uric acid induced ROS production as assessed by $\mathrm{H}_{2} \mathrm{O}_{2}$ staining from $30 \mathrm{~min}$, with an increased activity of NOX in a timedependent manner (Figures $6 \mathrm{a}$ and $\mathrm{b}$ ). Consistent with NOX activation, uric acid induced $\mathrm{p} 47^{\text {phox }}$ phosphorylation and $\mathrm{p}-\mathrm{p} 47^{\text {phox }}-\mathrm{p} 22^{\text {phox }}$ interaction, which was blocked by probenecid. Rapid phosphorylation of $\mathrm{p} 47^{\text {phox }}$ by uric acid suggests that this subunit is required for enhanced activity of NADPH oxidase by uric acid in HepG2 cells.

Mitochondrial ROS production assessed by MitoSOX staining was also observed $6 \mathrm{~h}$ following uric acid stimulation (Figure 9). NAC (an ROS scavenger) or DPI (a NOX inhibitor) blocked the expression of GRP78/94, ATF6, p-PERK, p-eIF- $2 \alpha$, and XBP- 1 splicing at $1-24 \mathrm{~h}$, suggesting that the
ROS production by NOX in uric acid-exposed cells preceded the development of ER stress. Rotenone (mitochondrial complex I inhibitor) did not alter the expression of ER stress markers at earlier time points up to $6 \mathrm{~h}$; however, rotenone ameliorated uric acid-induced ER stress at 12 and $24 \mathrm{~h}$. These findings suggested that cytoplasmic ROS by membranous NOX activation was responsible for uric acid-induced ER stress in earlier time points, whereas mitochondrial ROS also played a role in later time points in fat accumulation in HepG2 cells. Mitochondrial oxidative stress, which is generally known to occur later than ROS production by membranous NOX activation, and which can be also induced by membranous NOX-mediated ROS in part, is reported as a key mechanism of hepatic steatosis. ${ }^{30,31}$ In our study, TUDCA ameliorated mitochondrial ROS production (Figure 9), suggesting ER stress preceded mitochondrial dysfunction. Antioxidants, NAC, DPI, and rotenone alleviated uric acidinduced TG accumulation in HepG2 cells.

In summary, we propose that uric acid generated from intracellular metabolism or via entry from the circulation activates NOX in cell membranes with ROS production, which induces a cascade of ER stress with a release of mature form of lipogenic transcription factor, SREBP-1c. Mitochondrial ROS, which was proven to be major mechanism of hepatic lipogenesis in a previous study from our group, ${ }^{13} \mathrm{can}$ be produced by ER dysfunction as well as ROS accumulated by membranous NOX activation. Therefore, there is a cross-talk between oxidative stress and ER stress in uric acid-exposed hepatocytes, which resulted in an enhanced expression of lipogenic genes and TG production (Figure 11).

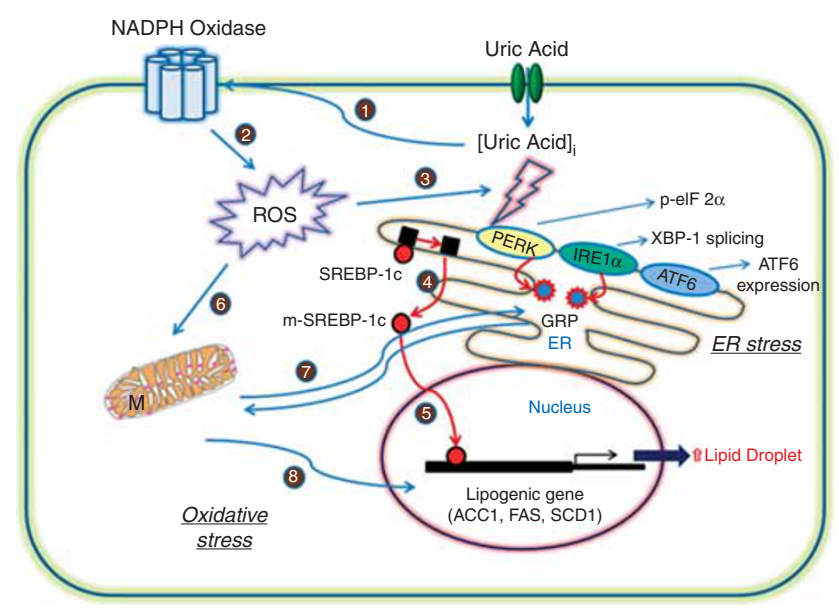

Figure 11 Proposed model of uric acid-induced fat accumulation through ER stress. After entering into hepatocytes, uric acid activates NOX (1) and induces membranous NOX-dependent ROS production (2), which stimulates UPR in ER (3). Enhanced UPR induces SREBP-1c cleavage into mature form (4), which is translocated into nucleus and activates the transcription of lipogenic genes (ACC1, FAS, and SCD1) (5). NOXdependent ROS further activates mitochondrial ROS production (6), which can also be activated by ER stress and vice versa (7). Mitochondrial ROS is also reported to be an important mechanism of TG accumulation in hepatocyte (8). ${ }^{13}$ 
In conclusion, our study provides the first evidence that uric acid-induced fat accumulation in HepG2 cells or primary hepatocytes occurs by oxidative and ER stress. Effect of uric acid-lowering therapy on fat accumulation needs to be examined in an animal model of fatty liver. We also propose studies in humans to determine whether lowering uric acid may provide a beneficial effect for preventing and/or treating NAFLD and metabolic syndrome.

\section{ACKNOWLEDGMENTS}

This study was supported by the grant from the Korea Healthcare Technology R\&D Project, Ministry for Health, Welfare \& Family Affairs, Republic of Korea (A101742), the National Research Foundation of Korea (NRF) grant funded by the Korea Government (MEST) (2010-0019866, 2012R1A2A2A01013541), Hi Seoul Science (Humanities) Fellowship funded by Seoul Scholarship Foundation, and the Ewha Global Top 5 Grant 2013 of Ewha Womans University.

\section{DISCLOSURE/CONFLICT OF INTEREST}

Dr RJJ has a patent application related to blocking uric acid as a means to prevent fatty liver. He is also on the Scientific Board of XORT therapeutics. All the other authors declare no conflict of interest.

1. Angulo P. Nonalcoholic fatty liver disease. N Engl J Med 2002;346: 1221-1231.

2. Greenfield V, Cheung O, Sanyal AJ. Recent advances in nonalcholic fatty liver disease. Curr Opin Gastroenterol 2008;24:320-327.

3. Pagliassotti MJ. Endoplasmic reticulum stress in nonalcoholic fatty liver disease. Annu Rev Nutr 2012;32:17-33.

4. Werstuck GH, Lentz SR, Dayal S, et al. Homocysteine-induced endoplasmic reticulum stress causes dysregulation of the cholesterol and triglyceride biosynthetic pathways. J Clin Invest 2001;107:1263-1273.

5. Oyadomari S, Harding HP, Zhang Y, et al. Dephosphorylation of translation initiation factor 2alpha enhances glucose tolerance and attenuates hepatosteatosis in mice. Cell Metab 2008;7:520-532.

6. Rutkowski DT, Wu J, Back SH, et al. UPR pathways combine to prevent hepatic steatosis caused by ER stress-mediated suppression of transcriptional master regulators. Dev Cell 2008:15:829-840.

7. Lee JS, Mendez R, Heng HH, et al. Pharmacological ER stress promotes hepatic lipogenesis and lipid droplet formation. Am J Transl Res 2012;4:102-113.

8. Zhang C, Chen X, Zhu RM, et al. Endoplasmic reticulum stress is involved in hepatic SREBP-1c activation and lipid accumulation in fructose-fed mice. Toxicol Lett 2012;212:229-240.

9. Ozcan U, Yilmaz E, Ozcan L, et al. Chemical chaperones reduce ER stress and restore glucose homeostasis in a mouse model of type 2 diabetes. Science 2006:313:1137-1140.

10. Yang JS, Kim JT, Jeon J, et al. Changes in hepatic gene expression upon oral administration of taurine-conjugated ursodeoxycholic acid in ob/ob mice. PLoS One 2010;5:e13858.

11. Sirota JC, McFann K, Targher G, et al. Elevated serum uric acid levels are associated with non-alcoholic fatty liver disease independently of metabolic syndrome features in the United States: Liver ultrasound data from the National Health and Nutrition Examination Survey. Metabolism 2013:62:392-399.

12. Ryu S, Chang Y, Kim SG, et al. Serum uric acid levels predict incident nonalcoholic fatty liver disease in healthy Korean men. Metabolism 2011;60:860-866
13. Lanaspa MA, Sanchez-Lozada LG, Choi YJ, et al. Uric acid induces hepatic steatosis by generation of mitochondrial oxidative stress: potential role in fructose-dependent and -independent fatty liver. J Biol Chem 2012;287:40732-40744.

14. $\mathrm{Xu} \mathrm{CF}, \mathrm{Yu} \mathrm{CH}, \mathrm{Xu}$, et al. Hypouricemic therapy: a novel potential therapeutic option for nonalcoholic fatty liver disease. Hepatology 2010;52:1865-1866.

15. Lanaspa MA, Sanchez-Lozada LG, Cicerchi C, et al. Uric acid stimulates fructokinase and accelerates fructose metabolism in the development of fatty liver. PLoS One 2012;7:e47948.

16. Katsurada $\mathrm{A}$, Iritani $\mathrm{N}$, Fukuda $\mathrm{H}$, et al. Effects of nutrients and insulin on transcriptional and post-transcriptional regulation of glucose-6phosphate dehydrogenase synthesis in rat liver. Biochim Biophys Acta 1989;1006:104-110.

17. Katsurada $\mathrm{A}$, Iritani $\mathrm{N}$, Fukuda $\mathrm{H}$, et al. Effects of nutrients and hormones on transcriptional and post-transcriptional regulation of acetyl-CoA carboxylase in rat liver. Eur J Biochem 1990;190:435-441.

18. Ntambi JM. Dietary regulation of stearoyl-CoA desaturase 1 gene expression in mouse liver. J Biol Chem 1992;267:10925-10930.

19. Dentin R, Pegorier JP, Benhamed F, et al. Hepatic glucokinase is required for the synergistic action of ChREBP and SREBP-1C on glycolytic and lipogenic gene expression. J Biol Chem 2004;279: 20314-20326.

20. Ishii S, lizuka K, Miller BC, et al. Carbohydrate response element binding protein directly promotes lipogenic enzyme gene transcription. Proc Natl Acad Sci USA 2004;101:15597-15602.

21. Park JW, Park WJ, Kuperman Y, et al. Ablation of very long acyl chain sphingolipids causes hepatic insulin resistance in mice due to altered detergent-resistant membranes. Hepatology 2013;57: 525-532.

22. Zigdon H, Kogot-Levin A, Park JW, et al. Ablation of ceramide synthase 2 causes chronic oxidative stress due to disruption of the mitochondrial respiratory chain. J Biol Chem 2013;288:4947-4956.

23. Lee $\mathrm{K}$, Tirasophon $\mathrm{W}$, Shen $\mathrm{X}$, et al. IRE1-mediated unconventional mRNA splicing and S2P-mediated ATF6 cleavage merge to regulate XBP1 in signaling the unfolded protein response. Genes Dev 2002;16:452-466.

24. Li Y, Xu S, Mihaylova MM, et al. AMPK phosphorylates and inhibits SREBP activity to attenuate hepatic steatosis and atherosclerosis in diet-induced insulin-resistant mice. Cell Metab 2011;13:376-388.

25. Lee $A H$, Scapa EF, Cohen DE, et al. Regulation of hepatic lipogenesis by the transcription factor XBP1. Science 2008;320:1492-1496.

26. Foufelle F, Ferre $P$. New perspectives in the regulation of hepatic glycolytic and lipogenic genes by insulin and glucose: a role for the transcription factor sterol regulatory element binding protein-1c. Biochem J 2002;366(Pt 2):377-391

27. Dentin R, Girard J, Postic C. Carbohydrate responsive element binding protein (ChREBP) and sterol regulatory element binding protein-1C (SREBP-1c): two key regulators of glucose metabolism and lipid synthesis in liver. Biochimie 2005;87:81-86.

28. Sautin YY, Nakagawa T, Zharikov S, et al. Adverse effects of the classic antioxidant uric acid in adipocytes: NADPH oxidase-mediated oxidative/ nitrosative stress. Am J Physiol Cell Physiol 2007;293:C584-C596.

29. Sanchez-Lozada LG, Soto V, Tapia E, et al. Role of oxidative stress in the renal abnormalities induced by experimental hyperuricemia. Am J Physiol Renal Physiol 2008;295:F1134-F1141.

30. Dikalov S. Cross talk between mitochondria and NADPH oxidases. Free Radic Biol Med 2011;51:1289-1301.

31. Rector RS, Thyfault JP, Uptergrove GM, et al. Mitochondrial dysfunction precedes insulin resistance and hepatic steatosis and contributes to the natural history of non-alcoholic fatty liver disease in an obese rodent model. J Hepatol 2010;52:727-736. 